\title{
Impact of noncommunicable diseases in the State of Qatar
}

This article was published in the following Dove Press journal:

ClinicoEconomics and Outcomes Research

2 July 2015

Number of times this article has been viewed

\author{
Salma Khalaf Al-Kaabi \\ Andrew Atherton \\ Supreme Council of Health, \\ Doha, Qatar
}

Correspondence: Salma Khalaf Al-Kaabi Supreme Council of Health, Al Rumaila West, PO Box 42, Doha, Qatar Email skalkaabi@sch.gov.qa

\begin{abstract}
This study, commissioned by the Supreme Council of Health in the State of Qatar, focuses on the main noncommunicable diseases (NCDs) globally and regionally, in order to gauge their potential impact on Qatar. The research shows that the Gulf Cooperation Council is projected to be affected dramatically by NCDs in the coming years. The top five NCDs that will affect Qatar in terms of economic burden and disability-adjusted life years are cardiovascular diseases, mental health and behavioral disorders, cancer, respiratory diseases, and diabetes. Whilst these diseases have diverse effects on patients, their causes can be traced to "... common lifestyle-related, or behavioral, risk factors such as tobacco use, a diet heavy in fat, and physical inactivity". The total direct and indirect costs to the Gulf Cooperation Council calculated for the above five NCDs were $\$ 36.2$ billion in 2013 , which equates to $150 \%$ of the officially recorded annual health care expenditure. If this trajectory is maintained, spending per head of population in Qatar will reach $\$ 2,778$ by 2022 . These figures demonstrate not only the potential financial impact of the main NCDs, but also give an idea of how the current health system is working to address them.
\end{abstract}

Keywords: cardiovascular disease, mental health, cancer, diabetes, respiratory disease, national health strategy, State of Qatar

\section{Introduction}

Noncommunicable diseases (NCDs) and chronic illnesses affect all countries, including the Gulf Cooperation Council (GCC) countries, of which the State of Qatar is a member. The increase in prevalence of NCDs is largely attributable to changing demographics and adoption of the lifestyle of developed countries, ie, poor (high fat, high sugar) diet and insufficient exercise. ${ }^{1}$ It is well recognized that people suffering from NCDs have intensive and often costly health care needs.

It is a widely held view that countries with higher levels of national wealth have better health outcomes in terms of a healthier lifestyle, better diet, and access to better health care services. ${ }^{2,3}$ However, increased wealth can also have a negative impact on health as a result of poor lifestyle choices. This has been seen in the Western world through an increase in obesity, lack of exercise, and excessive energy consumption. Increasing prosperity around the world has led to a new wave of negative health impacts. It is therefore necessary to evaluate the increasing prevalence of NCDs, such as respiratory illness, cardiovascular diseases, and cancer, in the GCC countries in order to formulate appropriate responses.

\section{Defining NCDs}

NCDs are defined as diseases of "long duration, generally with slow progression". ${ }^{4}$ The leading NCDs are generally considered to be cardiovascular diseases, diabetes, 
cancer, and chronic respiratory diseases. ${ }^{5}$ Whilst these diseases are the main NCDs affecting world health, they do not cover all disease entities, with notable omissions being mental health disorders, vision and hearing impairments, and musculoskeletal diseases. Musculoskeletal diseases alone “can severely diminish one's capacity to undertake manual labor, such as farming, which is the dominant productive activity in rural settings that are home to $50 \%$ of the world's population". ${ }^{6}$ Further, the term "noncommunicable disease" may be regarded as somewhat of a misnomer, given that a proportion of NCDs can be transmitted from human to human, an example of this being human papillomavirus. ${ }^{7}$

\section{Burden of NCDs on health and well-being}

Overall, chronic NCDs were responsible for around $68 \%$ of the 56 million deaths recorded across the globe in $2012 .{ }^{4}$ Figure 1 shows the World Health Organization (WHO) classification of the four main NCDs, ie, cardiovascular diseases, chronic lung diseases, cancer, and diabetes, in terms of causes of death in $2012 .{ }^{4}$ In that year, cardiovascular disease alone was responsible for around 7.4 million deaths, respiratory cancers for 1.6 million $(2.7 \%)$ deaths, and diabetes for 1.5 million $(2.7 \%)$ deaths.

The same WHO statistics show that approximately $75 \%$ of deaths attributable to NCDs occurred in lowincome or middle-income countries. However, in relation to the percentage of deaths per country, ie, compared with the size of population, the most developed countries actually had the highest incidence $(87 \%)$ of all deaths from NCDs, followed by upper middle-income countries $(81 \%){ }^{4}$

The impact of NCDs is steadily increasing, and is affecting people of all ages in both developed and developing countries. According to WHO projections, deaths attributable to NCDs have increased globally by 7 million between 2000 and 2012.

From a standard of living perspective, NCDs tend to result in further impairments to the individual over time. The absolute numbers vary from study to study, but for diabetes it is estimated that

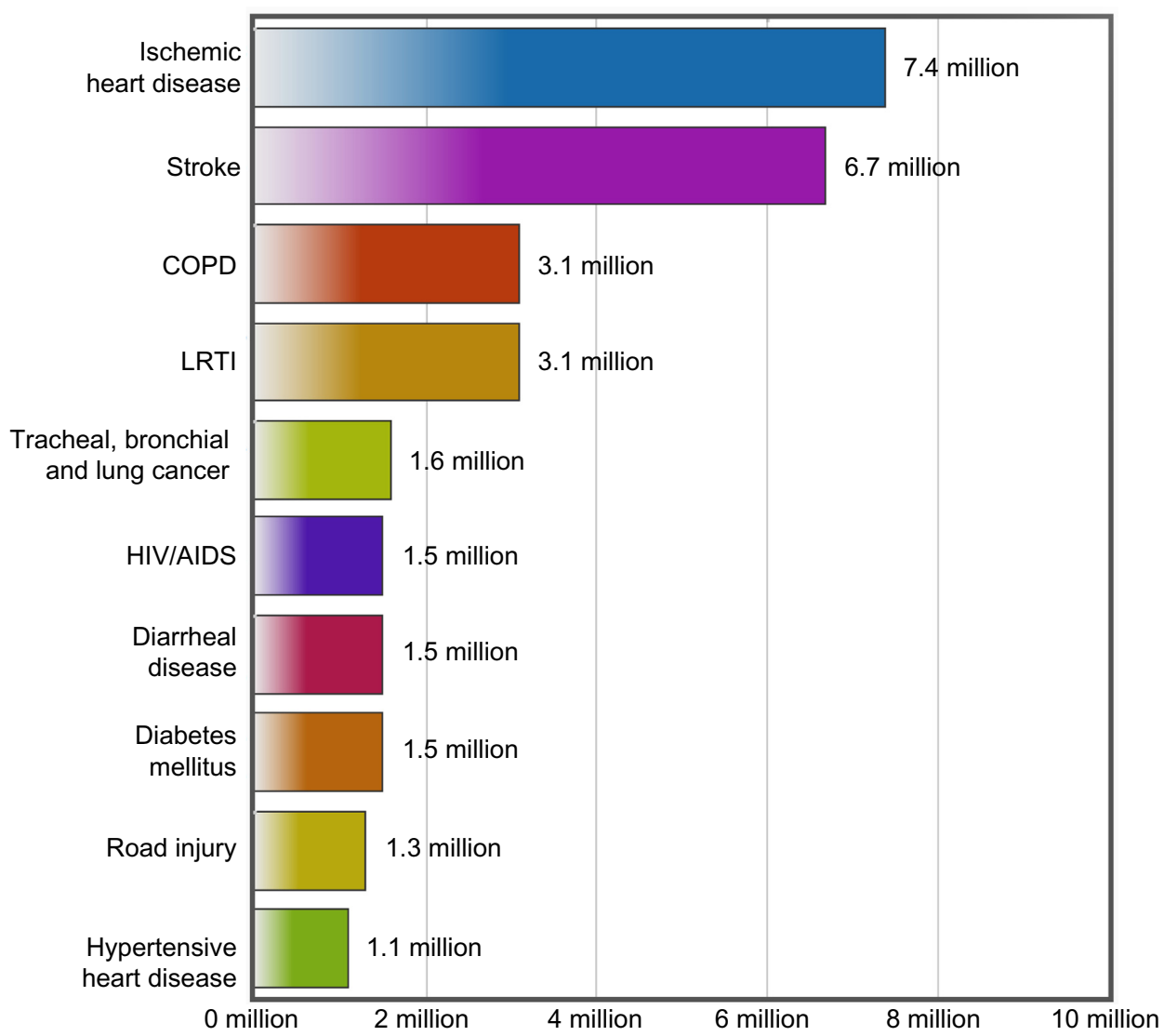

Figure I Top ten causes of death in the world in 2012.

Note: Reprinted from World Health Organization. The top 10 causes of Death. Available from: http://www.who.int/mediacentre/factsheets/fs3 I0/en/index2.html. Accessed October 20, 2014. ${ }^{4}$

Abbreviations: HIV, human immunodeficiency virus; AIDS, acquired immune deficiency syndrome; COPD chronic obstructive pulmonary disease; LRTI, lower respiratory tract infection. 
... between $13 \%$ to $65 \%$... will develop neuropathy, leading to chronic ulcerations and amputations in $1 \%$ to $17 \%$ of them; $10 \%$ to $47 \%$ of persons

living with diabetes will develop a retinopathy leading to visual impairment. ${ }^{8}$ These numbers become even more alarming when it is considered that the same research found that "... in 2004, there were 30.7 millions of people in the world living with impairments due to stroke, one of the conditions caused by cardiovascular risk factors". In broader terms, the effects on these individuals are far reaching, and

... they may be considered to have a disability when social, economic, political or other barriers hinder their full and effective participation in society. ${ }^{8}$

According to the Global Health Estimates study, ${ }^{9}$ NCDs are among the top ten causes of disability-adjusted life years. In relation to the global view of NCDs, heart disease ranked first in the list (6.0\%) in terms of disability-adjusted life years, followed by COPD (3.4\%), depressive disorders (2.8\%), and respiratory cancer $(1.4 \%)$.

It is believed that population health has been negatively affected as a result of the economic development currently taking place in GCC countries, ie, “... adopting a sedentary lifestyle among other unhealthy habits", which in turn has led to an increase in NCDs. ${ }^{10}$ It must be noted that whilst the issue is potentially more acute in the GCC region, this pattern mirrors global trends, with projections suggesting that NCDs will cause over $75 \%$ of all deaths globally by $2030 .{ }^{10}$

The top ten causes of death in high-income countries and the GCC region were found to be comparable, as shown in Figure $2 .{ }^{4}$ The data in this figure indicate that the disease burden in the GCC region is similar to the global burden, in that ischemic heart disease, which is first on the list, is responsible for 158 deaths per 100,000 population, followed by stroke, which accounts for around 95 deaths per 100,000 population. ${ }^{4}$ When relating these data to Qatar, it can be seen that the overall number of deaths declined between 2001 and 2007. This coincided with an increase in life expectancy from 77 in 2000 to 79 in $2012 .{ }^{9}$ This overall reduction in the actual number of deaths and the increase in life expectancy in Qatar (and in other GCC countries)

... reflect[s] the fact that Qatar has entered the epidemiological transition stage three; the age of non-communicable disease. ${ }^{11}$

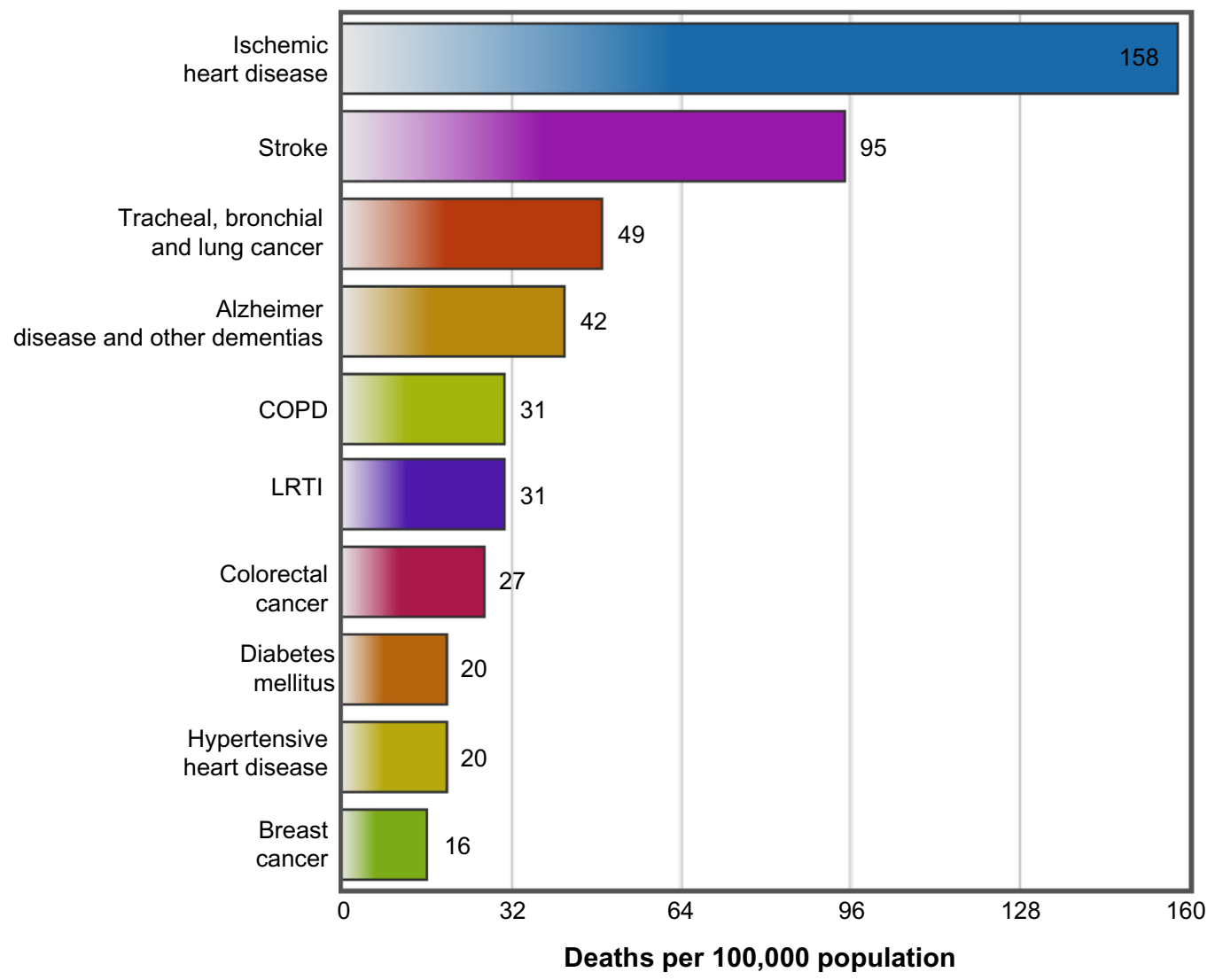

Figure 2 Ten leading causes of death in high income countries in 2012.

Note: Reprinted from World Health Organization. The top 10 causes of Death. Available from: http://www.who.int/mediacentre/factsheets/fs3 I0/en/index2.html. Accessed October 20, 2014. ${ }^{4}$

Abbreviations: COPD chronic obstructive pulmonary disease; LRTI, lower respiratory tract infection. 
In Qatar, NCDs have been the leading cause of death in the last 10 years. The Qatar STEPS report on risk factors for chronic disease highlighted that, during the period 2004-2010, the top four NCDs in terms of cause of death (Figure 3) were

... diseases of the circulatory system, neoplasm, endocrine, nutritional and metabolic diseases, diseases of the respiratory system. ${ }^{11}$

According to the Global Health Estimates study in 2011, NCDs are among the ten leading causes of disability-adjusted life years in the Eastern Mediterranean region, including the GCC countries. ${ }^{4}$

\section{Economic burden of NCDs}

The concept of direct and indirect effects on health has led to consideration of the economic burden of NCDs, and work to date indicates that NCDs have a significant financial impact. ${ }^{10}$ Direct costs are "... associated with the treatment of patients, such as consultations, medications, and clinical operations", ${ }^{14}$ whereas indirect economic impacts have more far-reaching consequences that

... reduce life expectancy, this means less output affect and causes less contribution in economic activities. Labor productivity is diminished due to workers inefficiency and constant absence. ${ }^{11}$

Estimating the size of these direct and indirect burdens of disease is difficult because of the range of measurement methods used..$^{10}$ In the World Economic Forum and Harvard School of Public Health study, the economic burden of NCDs was estimated using the cost of illness, EPIC (value of lost output), and value of statistical life models. An econometric model was developed during the

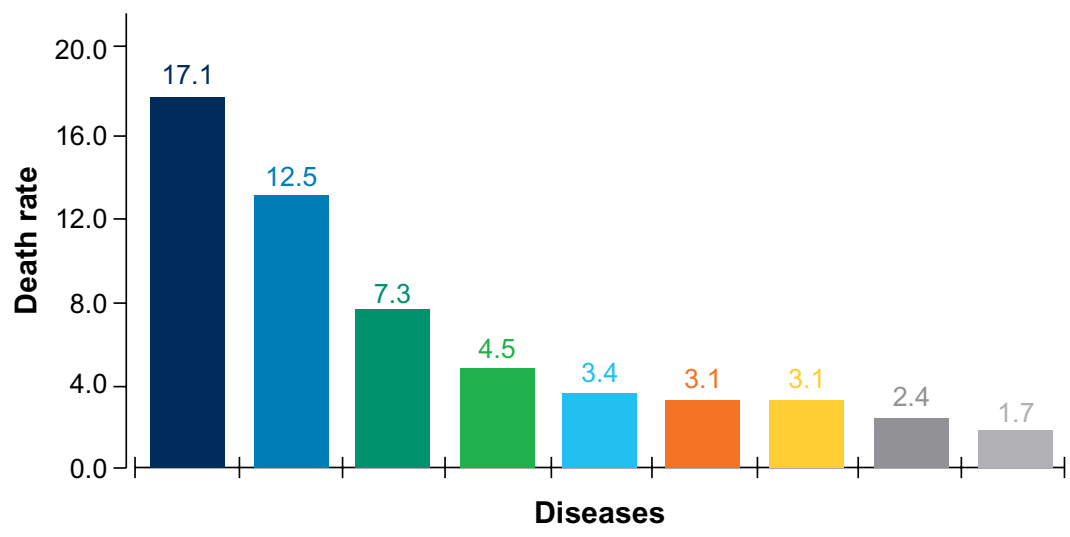

Diseases of the circulatory system

Neoplasms

Endocrine, nutritional and metabolic

Diseases of the respiratory system

Congenital malformations, deformations

Diseases of the digestive system

Certain conditions originating in perinatal period

Diseases of the genitourinary system

Certain infectious and parasitic diseases

Figure 3 Death rate by 100,000 population for the most common diseases leading to death in Qatar in $2010 .^{10}$

Note: Reproduced with permission from World Health Organization. Qatar STEPS Survey. 2012 Fact Sheet. Available from: http://www.who.int/chp/steps/Qatar FactSheet_2012.pdf. Accessed December 24, 2014."' 
study to calculate the cost of illness. ${ }^{6}$ This model is based on information that is more robust and readily available (such as the prevalence rates of the main NCDs), so the conclusions drawn can be regarded as more robust. Again, it should be noted that whilst the NCDs highlighted have different symptoms, they do share common lifestyle-related risk factors.

The total direct and indirect costs calculated for the five selected NCDs in 2013 was $\$ 36.2$ billion for the GCC region (Figure 4), which is 1.5 times the official health care spending..$^{10}$ The authors of the study also commented that if governments and policymakers do not intervene, up to $\$ 68$ billion could be consumed by 2022 . The burden is greater, and clearly less sustainable, when the total cost of NCDs is compared with health care spending.

The study predicted that, by 2022, the total cost per head for NCDs alone will reach \$2,778 in Qatar, compared with $\$ 603$ in Oman. This is all the more alarming when it is considered that the OECD (Organisation for Economic Co-operation and Development) countries spent \$3,327 per capita on all health care in $2011 .{ }^{10} \mathrm{~A}$ study by Chahine et al found that the direct cost for the five selected NCDs would be approximately $\$ 6$ billion in 2013 for the whole GCC, and projected this to escalate to $\$ 12.9$ billion over the following 9 years. ${ }^{10}$

Figure 5 highlights the effect of NCDs on the various components of the health economy, and this information should be used to plan future health systems and capacity. The direct costs indicate a large rise in outpatient activity but virtually no impact on hospital admissions, suggesting that whilst more clinic appointments will be required, a subsequent increase in bed numbers will not be necessary for these NCDs (Figure 5).

The cost of NCDs was presented comprehensively in the work undertaken by the World Economic Forum and Harvard School of Public Health in 2011.6 Three separate methods were used to calculate the burden of direct and indirect costs (Table 1). ${ }^{6}$ The first method was the cost-ofillness approach, which highlights the economic impact of disease by adding together the direct costs (eg, cost of treatment) and indirect costs (eg, absence from work) associated with an NCD. The second method is the economic

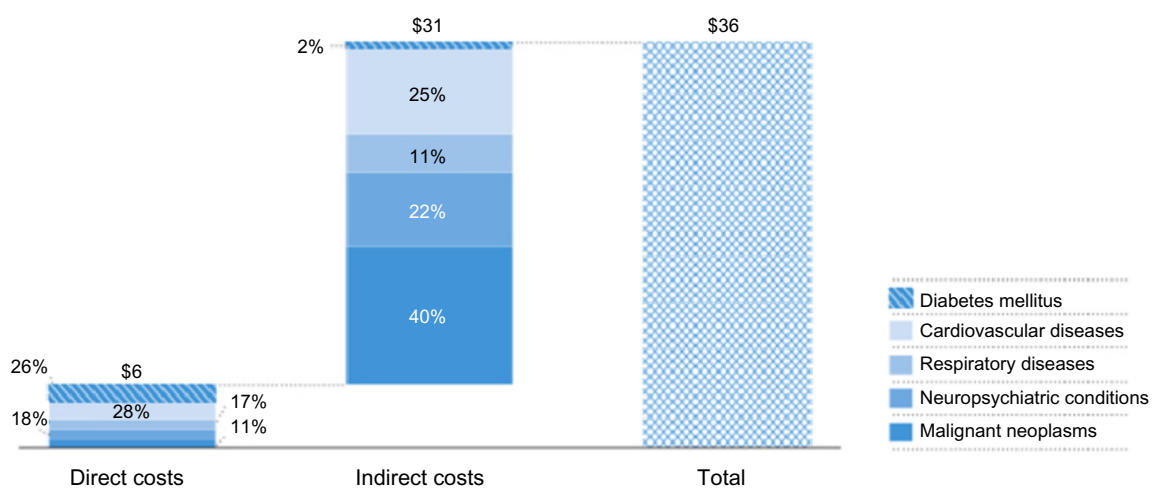

Figure 4 Direct and indirect costs of the five most prevalent noncommunicable diseases (in 20I3 \$US billion).

Note: Reproduced with permission from Chahine G, Bitar J, Assouad P, Abi Chaker S. The $\$ 68$ billion challenge, quantifying and tackling the burden of chronic diseases in the GCC. Booz \& Co; 2013. Available from: http://www.booz.com/me/home/thought_leadership_strategy/reports_and_white_papers_me/display/the-68-billion-dollar-

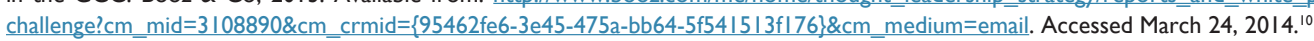
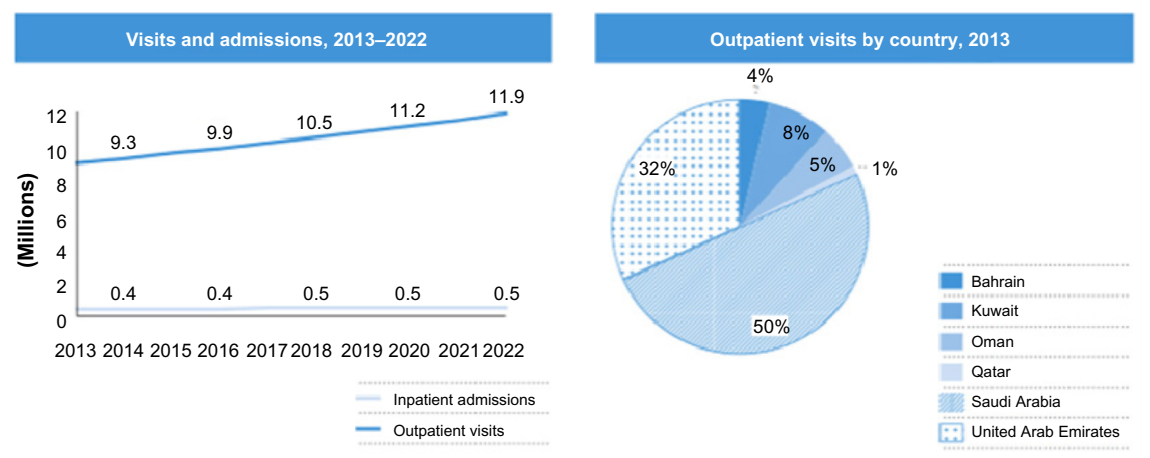

Figure 5 Visits and admissions for noncommunicable diseases in 20I3-2022.

Note: Reproduced with permission from Chahine G, Bitar J, Assouad P, Abi Chaker S. The $\$ 68$ billion challenge, quantifying and tackling the burden of chronic diseases in the GCC. Booz \& Co; 2013. Available from: http://www.booz.com/me/home/thought leadership_strategy/reports_and_white_papers_me/display/the-68-billion-dollarchallenge?cm_mid $=3108890 \& \mathrm{~cm} \_\mathrm{crmid}=\{95462 \mathrm{fe} 6-3 \mathrm{e} 45-475 \mathrm{a}-\mathrm{bb} 64-5 \mathrm{f} 54 \mathrm{I} 5 \mathrm{I}$ 3f 176$\} \& \mathrm{~cm}$ medium=email. Accessed March $24,2014 .{ }^{10}$ 
Table I Three separate methods were employed to calculate the burden of direct and indirect

\begin{tabular}{|c|c|c|}
\hline *Cost-of-illness approach & EPIC approach & **VSL approach \\
\hline $\begin{array}{l}\text { Estimates of direct and indirect costs of ill health } \\
\text { for five distinct disease categories are: }\end{array}$ & $\begin{array}{l}\text { Lost output from all five conditions (cancer, } \\
\text { cardiovascular disease, chronic respiratory diseases, }\end{array}$ & $\begin{array}{l}\text { Economic burden of life lost } \\
\text { due to all NCDs ranges from }\end{array}$ \\
\hline $\begin{array}{l}\text { Cancer: an estimated US\$ } 290 \text { billion in } 2010 \text { rising } \\
\text { to US\$ } 458 \text { billion in } 2030 \text {. }\end{array}$ & $\begin{array}{l}\text { diabetes, and mental health) over the period } 20 \mathrm{I} I-2030 \\
\text { is estimated at approximately US } \$ 47 \text { trillion. }\end{array}$ & $\begin{array}{l}\text { US\$ } 22.8 \text { trillion in } 2010 \text { to } \\
\text { US\$ } 43.3 \text { trillion in } 2030 \text {. }\end{array}$ \\
\hline
\end{tabular}

Cardiovascular disease: an estimated US\$ 863 billion

in 2010 rising to US\$1.04 trillion in 2030.

COPD: an estimated US\$2.I trillion in 2010 US\$

rising to US\$ 4.8 trillion in 2030 .

Diabetes: an estimated nearly US $\$ 500$ billion in

2010 rising to at least US\$ 745 billion in 2030 .

Mental illness: an estimated US\$ 2.5 trillion

in 2010 rising to US\$ 6.0 trillion by 2030 .

Notes: *The cost as the sum of direct and indirect costs (including personal medical; non-medical costs, and income losses); **Value of statistical life (VSL) approach (reflects a population's willingness to pay to reduce the risk of disability or death associated). Reproduced with permission from Bloom, D.E., Cafiero, E.T., Jané-Llopis, E., AbrahamsGessel, S., Bloom, L.R., Fathima, S., Feigl, A.B., Gaziano, T., Mowafi, M., Pandya, A., Prettner, K., Rosenberg, L., Seligman, B., Stein, A.Z., \& Weinstein, C. (20I I). The Global Economic Burden of Noncommunicable Diseases. Geneva: World Economic Forum. ${ }^{6}$

Abbreviations: COPD, chronic obstructive pulmonary disease; NCDs, noncommunicable diseases; VSL, value of statistical life; EPIC, European Prospective Investigation into Cancer and Nutrition.

Table 2 Economic burden of noncommunicable diseases for 20II-20I3 (trillions of US\$), based on the EPIC model

\begin{tabular}{|c|c|c|c|c|c|c|}
\hline $\begin{array}{l}\text { Country } \\
\text { income group }\end{array}$ & Diabetes & $\begin{array}{l}\text { Cardiovascular } \\
\text { diseases }\end{array}$ & $\begin{array}{l}\text { Chronic respiratory } \\
\text { diseases }\end{array}$ & Cancer & $\begin{array}{l}\text { Mental } \\
\text { illness* }\end{array}$ & Total \\
\hline High & 0.9 & 8.5 & 1.6 & 5.4 & 9.0 & 25.5 \\
\hline Upper-middle & 0.6 & 4.8 & 2.2 & 2.3 & 5.1 & 14.9 \\
\hline Lower-middle & 0.2 & 2.0 & 0.9 & 0.5 & 1.9 & 5.5 \\
\hline Low & 0.0 & 0.3 & 0.1 & 0.1 & 0.3 & 0.9 \\
\hline LIMIC & 0.8 & 7.1 & 3.2 & 2.9 & 7.3 & 21.3 \\
\hline World & 1.7 & 15.6 & 4.8 & 8.3 & 16.3 & 46.7 \\
\hline
\end{tabular}

Notes: *Numbers for mental illness were obtained by relating the economic burden of all other diseases to their associated number of disability-adjusted life years; the burden for mental illness was then projected using the relative size of the corresponding disability-adjusted life year numbers to all other conditions. "Lost output from all five conditions (cancer, cardiovascular disease, chronic respiratory diseases, diabetes and mental health) over the period $201 \mathrm{I}-2030$ is estimated at approximately US\$ 47 trillion. Reproduced with permission from Bloom, D.E., Cafiero, E.T., Jané-Llopis, E., Abrahams-Gessel, S., Bloom, L.R., Fathima, S., Feigl, A.B., Gaziano, T., Mowafi, M., Pandya, A., Prettner, K., Rosenberg, L., Seligman, B., Stein, A.Z., \& Weinstein, C. (20II). The Global Economic Burden of Noncommunicable Diseases. Geneva: World Economic Forum. ${ }^{6}$

Abbreviations: LIMIC, less indebted middle income countries; EPIC, European Prospective Investigation into Cancer and Nutrition.

growth approach, which is the value of lost output (in terms of economic activity). The final measure is the value of statistical life approach, which calculates the likelihood that people would pay to eliminate or reduce the effects of an NCD on their health.

The various methods highlighted have very separate inputs and therefore should not be used to evaluate the economic impact or one measure against another. Additionally, implementing each of these methods requires making various assumptions whilst recognizing that there are several issues with data quality from GCC sources. ${ }^{11}$ However, the various methodologies are obviously the scale of impact of NCDs and the undoubtedly significant impact on health expenditure.

The World Economic Forum and the Harvard School of Public Health report reached some important conclusions. Firstly, the global output will suffer considerably, with richer countries suffering more financial burden than poorer countries. ${ }^{5}$ Secondly, mental health conditions and cardiovascular diseases cost society the most, perhaps without this being widely recognized in the case of mental health.

Table 3 Noncommunicable disease mortality and DALY criteria

\begin{tabular}{llll}
\hline Diseases & *Mortality rate & & **DALY \\
\cline { 2 - 2 } $\begin{array}{l}\text { Cardiovascular diseases } \\
\text { (IHD and stroke) }\end{array}$ & $\mathrm{I}$ & Regional \\
$\begin{array}{l}\text { Cancer (lung, including tracheal } \\
\text { and bronchial) }\end{array}$ & 2 & $\mathrm{I}$ \\
$\begin{array}{l}\text { Respiratory diseases (COPD) } \\
\text { Mental and behavioral disorders }\end{array}$ & 3 & & 3 \\
Diabetes & - & \\
\hline
\end{tabular}

Notes: Table represents the ranking of these diseases in the order they appear regionally; *Death rate per 100,000 population; **Disability Adjusted Life Years, the sum of years of potential life lost due to premature mortality and the years of productive life lost due to disability.

Abbreviations: COPD, chronic obstructive pulmonary disease; DALY, disabilityadjusted life years; IHD, ischemic heart disease. 
Table 4 Regional ranking of noncommunicable diseases according to economic burden criteria

\begin{tabular}{|c|c|c|c|c|}
\hline \multirow[t]{2}{*}{ Diseases } & \multicolumn{2}{|c|}{ Cost of illness } & \multirow{2}{*}{$\begin{array}{l}\text { Anticipated economic } \\
\text { burden based on EPIC\# } \\
\text { approach } 201 \mathrm{I}-2030\end{array}$} & \multirow{2}{*}{$\begin{array}{l}\text { Output losses using } \\
\text { VSL approach } \\
(2010 \text { and } 2030)\end{array}$} \\
\hline & $\begin{array}{l}\text { Direct } \\
\text { cost }\end{array}$ & $\begin{array}{l}\text { Indirect } \\
\text { cost }\end{array}$ & & \\
\hline Cardiovascular diseases (IHD and stroke) & I & 2 & 2 & 2 \\
\hline Cancer (lung, including tracheal and bronchial) & 5 & 1 & 3 & 3 \\
\hline Respiratory diseases (COPD) & 4 & 4 & 4 & 4 \\
\hline Mental and behavioral disorders & 3 & 3 & I & 1 \\
\hline Diabetes & 2 & 5 & 5 & 5 \\
\hline
\end{tabular}

Note: Table represents the ranking of these diseases in the order they appear regionally. "Lost output from all five conditions (cancer, cardiovascular disease, chronic respiratory diseases, diabetes and mental health) over the period 20I I-2030 is estimated at approximately US\$ 47 trillion. Reproduced with permission from Bloom, D.E., Cafiero, E.T., Jané-Llopis, E., Abrahams-Gessel, S., Bloom, L.R., Fathima, S., Feigl, A.B., Gaziano, T., Mowafi, M., Pandya, A., Prettner, K., Rosenberg, L., Seligman, B., Stein, A.Z., \& Weinstein, C. (20II). The Global Economic Burden of Noncommunicable Diseases. Geneva: World Economic Forum. ${ }^{6}$

Abbreviations: COPD, chronic obstructive pulmonary disease; IHD, ischemic heart disease; VSL, value of statistical life; EPIC, European Prospective Investigation into Cancer and Nutrition.

\section{Prioritization strategy}

For the purposes of analyzing the potential impact of the four leading NCDs in the GCC region, including Qatar, mortality and disability-adjusted life years (Table 3 ) and economic burden (Table 4) have been used. This exercise will help the government to allocate financial and health resources, to prevent NCDs, identify people at risk and screen them, address the causes of NCDs, and prevent their complications.

However, cardiovascular disease is the leading cause of mortality and disability in the region, and mental and behavioral disorders are the second cause of disability. Cancer is ranked as the second cause of mortality and the third cause of disability, while respiratory diseases rank third as a cause of mortality and the third cause of disability. Mental health and cardiovascular disease account for almost $70 \%$, based on the EPIC model and shown in Figure 6 (these numbers represent a global figure, but the same ranking applies in GCC countries). The costs incurred by these diseases are shown in Table $2 .{ }^{6}$

\section{Conclusion and recommendations}

This work highlights the significant current and future impact of NCDs for Qatar and the wider region, as compared with the worldwide impact. ${ }^{13}$ This will still be a significant financial

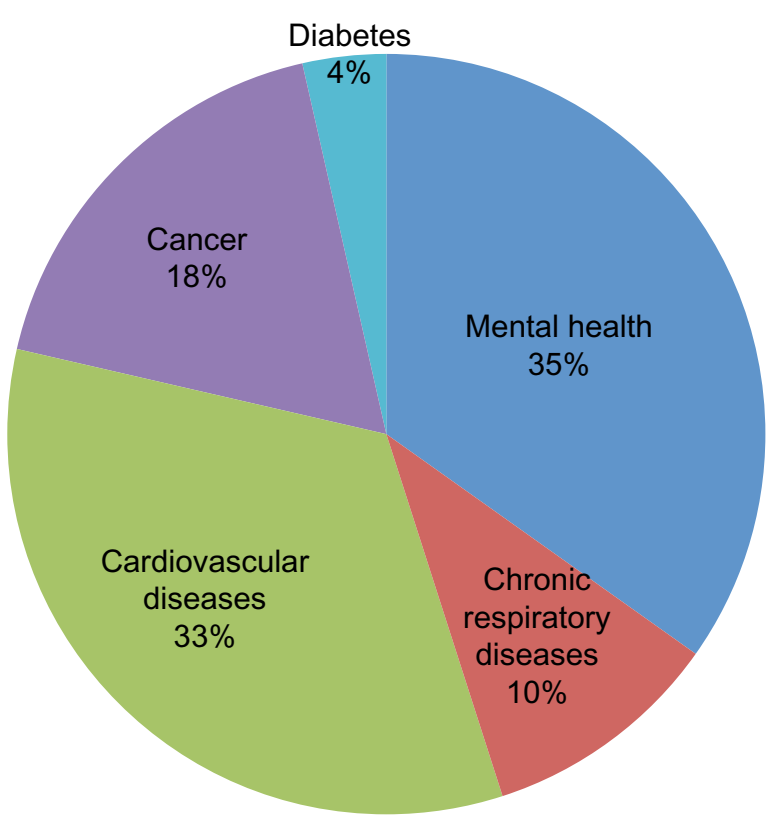

Figure 6 Top drivers of lost output. Breakdown of costs of noncommunicable diseases by disease type based on the EPIC model.

Note: Reproduced with permission from Bloom, D.E., Cafiero, E.T., Jané-Llopis, E., Abrahams-Gessel, S., Bloom, L.R., Fathima, S., Feigl, A.B., Gaziano, T., Mowafi, M., Pandya, A., Prettner, K., Rosenberg, L., Seligman, B., Stein, A.Z., \& Weinstein, C. (201I). The Global Economic Burden of Noncommunicable Diseases. Geneva: World Economic Forum. ${ }^{6}$

Abbreviation: EPIC, European Prospective Investigation into Cancer and Nutrition.

Table 5 Summary of high-impact disease in the Gulf region

\begin{tabular}{llll}
\hline Diseases & Mortality rate* & DALY** & Comparative Lost Output*** \\
\cline { 2 - 4 } & Regional & Regional & Globally \\
\hline Cardiovascular diseases (ischemic heart disease \& stroke) & 1 & 1 & $33 \%$ \\
Cancer (Lung cancers including trachea and bronchus cancers) & 2 & 3 & $18 \%$ \\
Respiratory diseases (COPD) & 3 & 4 & $10 \%$ \\
Mental and behavior disorders & - & 2 & $55 \%$ \\
Diabetes & 5 & 5 & $6 \%$ \\
\hline
\end{tabular}

Notes: Table represents the ranking of these diseases in the order they appear regionally. ${ }^{*}$ Death rate per 100000 population. **The sum of years of potential life lost due to premature mortality and the years of productive life lost due to disability. *** Quantifies global economic losses from NCDs by relating projected NCD mortality rates in a population to current and future economic output at the national level.

Abbreviations: DALY, disability-adjusted life years; COPD, chronic obstructive pulmonary disease; NCDs, noncommunicable diseases. 
burden for the region despite the fact that healthcare expenditure is predicted to reach US\$60 billion by $2025 .{ }^{14}$ The above discussion, on the whole, sets aside the impacts to the individual and their families brought about by the effects of long-term conditions and NCDs. These impacts should be sufficient to mandate governments to take action against NCDs; however, when compounded by the economic impact of NCDs, set against a background of an ageing population and increasing expectations of health care, these factors demonstrate the potential to have unaffordable health services in the future. ${ }^{15}$ Therefore, policymakers need to act both in terms of imposing a combination of shorter-term and longerterm measures, with short-term actions including "incentives and disincentives (such as taxes on tobacco), regulations (for example, limiting the availability of unhealthy food in schools), and clinical interventions (for instance, screening the population for risk factors)". ${ }^{10}$

Due to the size of the looming financial costs associated with NCDs, there also needs to be a comprehensive set of long-term measures; however, these will be much more difficult for policymakers to implement. These long-term measures must address cultural factors; for example, research has highlighted that the region's culture of hosting guests and eating out, along with its affluent lifestyle, has given rise to a much more sugar-based diet. ${ }^{16}$ Baglar emphasizes the need to change people's perceptions about being a good host, which are deeply entrenched in society, in association with increased education of patients about their Long Term Conditions. ${ }^{16}$

Chahine et al take the view that a larger set of measures is required to meet these issues in the longer term, and agree that "... programs [must] seek to change individual behavior", and further suggest that this needs to be done

... along with regulations and funding in the healthcare

system with a stress on preventative care [to] educate those

who care for children, inform adults, and raise awareness

among health providers about NCDs. ${ }^{10}$

They conclude that all sectors of the economy have a part to play, commenting that a "... wide range of stakeholders" would need to be involved; for example, the high-tech and food industries have a part to play in improving treatment and prevention through improving patient monitoring systems and more information on food packaging. ${ }^{10}$

Based on our report, the four top priority diseases identified as needing urgent action are cardiovascular disease, mental and behavior disorders, cancer, and chronic respiratory disease. Most NCDs can be traced back to lifestyle-related factors, such as smoking, diet, and lack of exercise. As such Qatar launched it's National Cancer Strategy (2011-2016), with recommendations covering tobacco cessation and nutrition and physical activity. The Supreme Council of Health launched its first national health strategy in 2011, which addresses the main challenges facing the health care system in Qatar, and highlights the need to move beyond treating the acutely ill and address health care at the prevention stage, with the aim to embed prevention and early intervention into every aspect of the health system, thereby empowering the people of Qatar to be active participants in self-care, prevention, and maintaining wellness. ${ }^{17}$

The Supreme Council of Health was established in 2009 by Emiri decree. Its main role is to “... oversee and regulate the medical market place and promote high quality health care" through evidence-based policies. ${ }^{18}$ The flagship strategy of the Supreme Council of Health is the Qatar National Health Strategy (NHS) for 2011-2016, which stems from the Qatar National Development Strategy 2030 launched in 2011: "The NHS proposes change across the healthcare system, through a practical national strategy for health reform designed to benefit all people currently living in Qatar as well as future generations." The NHS aims to address all key health issues affecting Qatar and to provide world-class health care for the future by building capacity and increasing quality across the health care sector. It is therefore necessary for the NHS to be working towards addressing the NCDs identified in this research.

Goal three of Qatar's NHS centers on embedding prevention into health service reforms; and focus on high-risk priorities (Table 5). ${ }^{17}$ Chronic disease management is prioritized within five main projects mentioned in the NHS, ie, a diabetes program, disease management programs, preventative health governance, nutrition and physical activity, mental health design, smoking cessation, a national screening program, and environmental health. Injuries, including road traffic accidents, are not considered in this report as one on the NCDs that need to be prioritized, since they are not included in the definition of NCD.

In conclusion, it is recommended that Qatar address cardiovascular and respiratory diseases in a more comprehensive way, so that we can prevent these diseases in the first place, manage cases appropriately, and prevent or manage the complications that arise. According to the results of the STEPwise survey, nutrition and physical activity as the main interventions that need to be addressed in an effective, 
innovative way. ${ }^{11}$ Nearly $33 \%$ of the population in Qatar has elevated blood pressure (systolic $\geq 140 \mathrm{mmHg}$ and/or diastolic $\geq 90 \mathrm{mmHg})^{19}$ or is currently on medication for raised blood pressure, according to World Health Organization standards. Given that cardiovascular disease is the highest ranked disease in term of mortality, disability-adjusted life years, and economic burden, hypertension should be approached in a systematic way to be able to coordinate heath care interventions and communicate at both the individual organization and national level. Urgent comprehensive and collaborative efforts are needed, with appropriate monitoring and assessment tools to determine the cost-effectiveness of intervention.

\section{Acknowledgments}

The authors would like to thank His Excellency Abdullah Bin Khalid Al Qahtani, Minister for Public Health; Dr Salih Al Marri, Assistant Secretary General for Medical Affairs, The Supreme Council of Health; and the National Health Strategy Program Management Office of The Supreme Council of Health for supporting this research.

\section{Disclosure}

The authors are currently employed by the Supreme Council of Health, State of Qatar. The authors report no other conflicts of interest in this work.

\section{References}

1. Institute for Health Metrics and Evaluation. The global burden of disease: generating evidence, guiding policy - Middle East and North Africa Regional Edition. 2013. Available from: http://www. healthmetricsandevaluation.org/gbd/publications/policy-report/globalburden-disease-middle-east-north-africa. Accessed March 24, 2014.

2. Institute of Health Equity. Fair society, healthy lives: the Marmot review, 2010. Available from: http://www.instituteofhealthequity.org/Content/ FileManager/pdf/fairsocietyhealthylives.pdf. Accessed May 19, 2014.

3. Deaton A. The Great Escape: Health, Wealth, and the Origins of Inequality. Princeton, NJ, USA: Princeton Press; 2013.

4. World Health Organization. The top 10 causes of Death. Available from: http://www.who.int/mediacentre/factsheets/fs310/en/index2.html. Accessed October 20, 2014.

5. World Health Organization. Preventing chronic disease - a vital investment, 2005. Available from: http://www.who.int/chp/chronic_disease_ report/full_report.pdf. Accessed April 1, 2014.
6. Bloom DE, Cafiero ET, Jané-Llopis E, et al. The global economic burden of non-communicable diseases. Geneva, Switzerland: World Economic Forum; 2011. Available from: http://www.hsph.harvard.edu/ program-on-the-global-demography-of-aging/WorkingPapers/2012/ PGDA_WP_87.pdf. Accessed December 24, 2014.

7. National Cancer Institute. HPV and cancer, 2012. Available from: http:// www.cancer.gov/cancertopics/factsheet/Risk/HPV. Accessed April 1, 2014.

8. NCD Alliance. Disability and non-communicable diseases. 2011. Available from: http://www.ncdalliance.org/sites/default/files/resource_files/ Brief\%20-\%20\%20Disability\%20and\%20NCD.pdf. Accessed May 19, 2014.

9. World Health Organization. Global health estimates summary tables. 2013. Available from: http://www.who.int/healthinfo/global_burden disease/en/. Accessed March 10, 2014.

10. Chahine G, Bitar J, Assouad P, Abi Chaker S. The $\$ 68$ billion challenge, quantifying and tackling the burden of chronic diseases in the GCC. Booz \& Co; 2013. Available from: http://www.booz.com/me/ home/thought_leadership_strategy/reports_and_white_papers_me/ display/the-68-billion-dollar-challenge? $\mathrm{cm}_{-} \mathrm{mid}=3108890 \& \mathrm{~cm}$ crmid $=\{95462$ fe $6-3$ e $45-475 a-b b 64-5 f 541513 f 176\} \& \mathrm{~cm}_{-}$ medium=email. Accessed March 24, 2014.

11. World Health Organization. Qatar STEPS Survey. 2012 Fact Sheet. Available from: http://www.who.int/chp/steps/Qatar_FactSheet_2012. pdf. Accessed December 24, 2014.

12. LaVeist TA, Gaskin DJ, Richard P. The Economic Burden of Health Inequalities in the United States. 2009. Available from: http://www. unnaturalcauses.org/assets/uploads/file/BurdenOfHealth.pdf. Accessed February 19, 2015.

13. Strategy\&. GCC governments must develop national and GCC-wide: non-communicable diseases (NCDs) agendas. 2013. Available from: http://www.booz.com/me/home/press_media/management_consulting_ press_releases/article/53207812. Accessed March 10, 2014.

14. Mourshed M, Hediger V, Lambert T. Gulf Cooperation Council health care: challenges and opportunities. 2007. Available from: http:// middleeasthospital.com/GCC\%20HEALTHCARE\%20CHALLENGE. pdf. Accessed May 19, 2014.

15. Deloitte. Global Health Care Outlook. Shared challenges, shared opportunities. 2014. Available from: https://www2.deloitte.com/content/ dam/Deloitte/global/Documents/Life-Sciences-Health-Care/dttl-lshc2014-global-health-care-sector-report.pdf. Accessed May 19, 2014.

16. Baglar R. 'Oh God, Save us from Sugar': An Ethnographic Exploration of Diabetes Mellitus in the United Arab Emirates. Abu Dhabi, United Arab Emirates: Taylor \& Francis; 2013.

17. Supreme Council of Health. National Health Strategy 2011-2013. Caring for the future. Executive Update 2013. Available from: http:// www.nhsq.info/app/media/325. Accessed March 26, 2014.

18. Supreme Council of Health. Supreme Council of Health, about us, 2014. Available from: http://www.sch.gov.qa/about-sch. Accessed February 19, 2015.

19. World Health Organization. Country (Site) STEPS Survey. 2012 Available from: http://www.who.int/chp/steps/Part6_Section3B.pdf. Accessed March 10, 2014.
ClinicoEconomics and Outcomes Research

\section{Publish your work in this journal}

ClinicoEconomics \& Outcomes Research is an international, peerreviewed open-access journal focusing on Health Technology Assessment, Pharmacoeconomics and Outcomes Research in the areas of diagnosis, medical devices, and clinical, surgical and pharmacological intervention. The economic impact of health policy and health systems

\section{Dovepress}

organization also constitute important areas of coverage. The manuscript management system is completely online and includes a very quick and fair peer-review system, which is all easy to use. Visit http://www.dovepress.com/testimonials.php to read real quotes from published authors. 